Xue Liu, Xiaofeng Xiang, Lan Jiang, Shuru Zhao

\title{
How to Improve the Performance of R\&D Alliance? An Empirical Analysis Based on China's Pharmaceutical Industry
}

\author{
(C) Higher Education Press and Springer-Verlag 2010
}

\begin{abstract}
The separation of science resources and the manufacturing industry in China has given rise to $R \& D$ alliances between $R \& D$ institutes and sponsoring enterprises. As a result, $R \& D$ alliance of various types has become a main route of technology innovation in China. Drawing upon relevant literature on R\&D alliance management, this research empirically explores the impacts of relationship pattern, control strategy chosen by sponsoring enterprises, and alliance members' continuity expectation on alliance performance. Results show that motivation-based alliance control approaches, including proper allocation of alliance control rights, sustained strengthening of alliance members' continuity expectation, and enhancement of mutual relationship and friendship among alliance members, are more effective than process or outcome control approaches for improving alliance performance.
\end{abstract}

Translated from Guanli Xuejia 管理学家 (学术版) (Management Magazine (Academic)), 2008, (4): $316-326$

Xue Liu

Guanghua School of Management, Peking University, Beijing 100871, China

E-mail: xueliu@gsm.pku.edu.cn

Xiaofeng Xiang $(\square)$

Guanghua School of Management, Peking University, Beijing 100871, China

E-mail: xiaofeng_xiang@yahoo.com.cn

Lan Jiang

Office of Science \& Technology, Peking University, Beijing 100871, China

E-mail: jianglan@pku.edu.cn

Shuru Zhao

Office of Science \& Technology, Peking University, Beijing 100871, China

E-mail: shrzhao@pku.edu.cn 
Keywords control, trust, relationship governance, continuity expectation, alliance performance

\section{Introduction}

The application of technology has long been regarded as one of the key driving factors for the modern economy, due to its promotion for the "increasing marginal return" of its own and other factors of production. In the modern society, most of the technology innovations are no longer achieved by any single enterprise but by joint cooperation between enterprises and scientific or research institutes. By forming alliances, enterprises and academic institutes are better able to achieve win-win situations. Although China has been attempting to optimize its science and technology resource allocation and has made great progress since its launch of reform and opening up in 1978, the chronic problem of "separation between science and technology resources and manufacturing capability" still remains unsolved. R\&D alliances between enterprises and research institutes have proved to be an effective solution to technology innovation. Statistics show that more than one third of traded new technologies have been created by these alliances (Liu, 2001).

$\mathrm{R} \& \mathrm{D}$ alliance refers to a certain type of contract-based cooperation between sponsor (usually enterprises) and researcher (usually science and research institutes). In many cases, R\&D alliance also means trading of anticipated technology prior to the innovation. Before the formation of technology alliance, there exists an information asymmetry between sponsors and R\&D institutes. However, even though a sponsor will gain more access to relevant information after their investment of money, there is still much room left for opportunistic behavior due to the inherent characteristics of uncertainty and complexity of technology innovation. Therefore, serious ethnical risks exist when alliances are poorly managed, which in turn will affect future alliance performance.

If sponsoring enterprises do not control and supervise the whole $R \& D$ process, $R \& D$ institutes are likely to use asymmetrical information to their advantage. For example, they might retain the invested money or use the money to other research projects, while attributing potential failures for uncertain and uncontrollable reasons. As for the sponsoring enterprises, it is difficult for them to supervise their R\&D partners in alliance due to the following reasons: First, it has been proved difficult to identify the real reason behind innovation failure. Second, it is very costly to control the R\&D process. In addition, any "improper" control is likely to damage the mutual trust between partners and weaken the motivation of researchers (Gulati, 1995; Andrew, Inkpen and Steven, 2004). To 
say the least, even if sponsors notice that there has been slackness in R\&D, they can hardly prove it to a third party, say a court, due to the above-mentioned uncertainty and complexity of R\&D technology activities. Therefore, there can be a high amount of ethical risks in R\&D alliance. Likewise, even though R\&D institutes signed a profit-sharing contract with sponsoring enterprises, the latter could still hide some of its sales revenue or profit from the former due to the same problems of information asymmetry and "difficulty to prove". Therefore, sponsoring enterprises are also equally likely to commit opportunistic behaviors. Due to these reasons, how to control ethical risks and improve R\&D performance has long remained a problem harassing both researchers and practitioners alike.

As a whole, although great attention has been attached to $R \& D$ alliance research in western literature, little progress has been achieved in terms of alliance control strategies, and empirical study on the relationship between relationship governance and alliance performance is needed. Specifically, in literature of alliances in form of joint venture, most of study has focused on the relationships between joint-venture investors and shareholders in the host countries and the impact of such relationships on alliance performance (e.g., Das and Teng, 2002); in literature of non-equity alliances, most study has focused on the alliance relationship between enterprises and their suppliers and agents (Lui and Ngo, 2004). There has been a lack of empirical study, both at home and abroad, on the relationship among control strategy, relationship governance and alliance relationship. Therefore, this article aims to, based on a review of relevant literature on R\&D alliance management, conduct a systematical and empirical study on the impacts of relationship mode choice of sponsors, control strategy, continuity expectation of parties involved in alliance performance. In doing so, we hope to be able to provide some useful advice in reducing alliance ethical risks and improving alliance performance.

The remainder of this article is arranged as follows: (1) a review of relevant literature on $R \& D$ alliance management, including control strategies based on organizational theory, incomplete contract theory, and relationship management theory. Several hypotheses are developed following the literature review and rationale; (2) we describe our data collection on $R \& D$ alliance performance in the pharmaceutical industry in China to verify our hypotheses; (3) conclusion and discussion are provided in the last section.

\section{Literature Review and Hypotheses}

There have been two frequently adopted solutions to reduce the ethical risks and to improve alliance performance: one is to strengthen control; the other is relationship governance (e.g., to reduce alliance risks and improve performance 
by means of building good mutual relationship among parties involved and by enhancing the continuing expectation of cooperation). Control methods can also be classified into control based on organizational theories and control based on incomplete contract theory. Below, based on a review of relevant literature, we will develop hypotheses on the management of ethical risks in R\&D alliance.

\subsection{Control Approach Based on Organizational Theories}

Control approach based on organizational theories (referred to as organizational control hereinafter) was firstly proposed by Ouchi (1979). He believed that the choice of control strategy is the function of task characteristics. The latter can be identified from two aspects: one is called task programmability, the other is called outcome measurability. When both aspects are of high levels, both behavior control and outcome control would be effective; when there is high level of task programmability but low level of outcome measurability, behavior control would achieve better results than outcome control and otherwise, outcome control would be more effective. When there are low levels of both task programmability and outcome measurability, socialized control or clan control would be more effective. In other words, it would be easier to control R\&D alliance by means of building mutually-shared value, ideas, preference, and behavior mode.

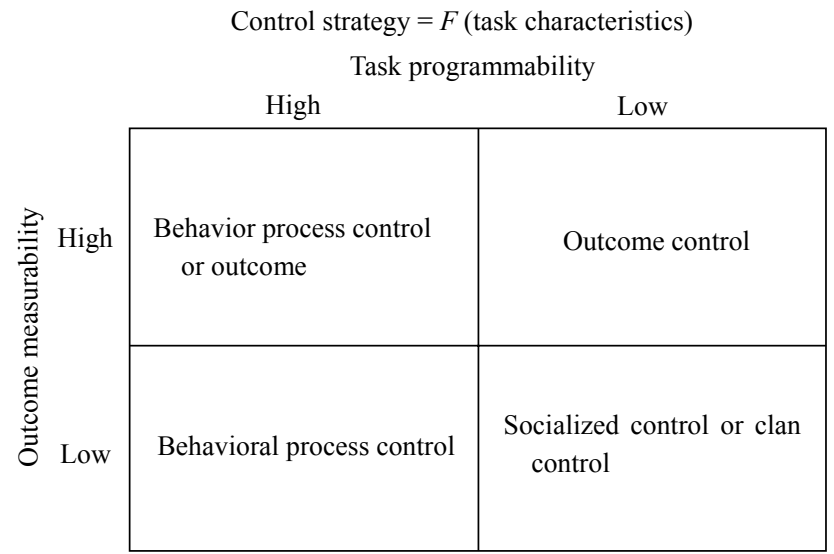

Fig. 1 Relationship between Control Strategy Choice and Task Characteristics Note: Adopted from Ouchi (1979).

The relationship between control strategy choice and task characteristics is obvious. First, when tasks are highly standardized, it is easier to define "optimal behaviors". As a result, it is possible to control the observation and evaluation of behavioral process. Second, when the degree of task programmability declines, it 
will be more difficult for behavior observation to function as a reliable foundation for control strategy choice for principals are unable to define the "valid behavior" of agents. Third, explicitly defined target means outcome are measurable. Accordingly, outcome-based appraisal, reward, and punishment can be used as basis for control strategy choice. Fourth, "unprogrammable" tasks imply invalid supervision mechanism and immeasurable outcomes. As a result, exterior motivation mechanisms are likely to be poor in efficiency. Under such circumstance, effective control strategy should be based on reciprocity and socialization. In other words, effective control strategy shall aim at reducing the differences in participants' preference and building mutually-shared value views and culture.

The key of successful organizational control lies in: (1) task characteristics, particularly the degree of task programmability, which greatly affects control cost and control cost will in turn affect choice of control strategy; (2) socialized control works as a substitute for process-and-performance-based control. As organizational control emphasizes that the choice of control strategy is an endogenous variable determined by task characteristics, will proper organizational control methods help reduce ethnical risks in R\&D alliances?

Innovation is "an iterative process initiated by the perception of a new market and/or new service opportunity for a technology based invention which lead to development, production, and marketing tasks striving for the commercial success of the invention" (OECD, 1991). Consisting of both the R\&D step and marketing step (bringing the new innovation to the hands of end users), innovation process is characterized by uncertainty. As a result, before reaching any agreement, it will be difficult to explicitly and precisely describe task objectives. Drawing on Ouchi's theory, we assume that

H1 In a R\&D alliance, the sponsoring enterprise's control over R\&D process is negatively related to $R \& D$ performance.

H2 In a R\&D alliance, the sponsoring enterprise's control over R\&D innovation outcome is negatively related to $R \& D$ performance.

As above, when a task is difficult to programme and outcome are difficult to measure, social or clan control strategies are always adopted. However, even within the border of an enterprise, it usually takes a long time to cultivate mutually shared value and ethics (and usually without success). Loosely connected in a R\&D alliance, sponsoring enterprises and research institutes vary greatly in culture, ideology, and code of behavior, which makes it more difficult for socialized control to be adopted (especially within the short life scope of $\mathrm{R} \& \mathrm{D}$ alliance). Therefore, this article will not talk about the validity of socialized control. 


\subsection{Control Method based on the Incomplete Contract Theory}

Control theory based on the incomplete contract theory (Grossman and Hart, 1986) is referred to by Eisenhardt (1985) as an "economic approach of control".

Grossman and Hart divided contracted rights into specific rights and surplus rights. The former means clearly-defined rights in a contract; the latter means rights not defined in a contract. Due to the existence of so-called contract cost, when it is too expensive to note down every right in a contract, surplus rights become a better choice. Ownership rights refer to the purchase of these rights. When being wrongly allocated, surplus rights would bring forth negative results. The optimal allocation of surplus rights depends on the comparative marginal utility rate of different investors, or the damage degree of underinvestment of any parties.

Drawing on Grossman and Hart's (1986), Aghion and Tirole (1994) believed that previous study did not correctly define the nature of innovation. Due to the high uncertainty of innovation process, $R \& D$ contract can not define clearly the innovation outcome, nor can it explain clearly the new-created value R\&D activity could bring to the sponsor. To the best, contract can define explicitly the amount of money sponsors need to invest, the intellectual property of possible innovation outcome and allocation rules of anticipated profit.

As contract of innovation cooperation is unable to define in advance the "material form" or "market value" of innovation, it is difficult to define and measure innovation outcome. In addition, innovation process is highly "unprogrammable". Therefore, economic control, i.e. to control by means of allocating property rights or surplus rights, seems to be a more effective approach. Based on the above rationale, Aghion and Tirole proposed the following propositions concerning optimal allocation of control rights of contract of innovation cooperation: in R\&D alliance, (1) when the marginal efficiency of the $R \& D$ institute is higher than that of the sponsoring enterprise, control rights should be allocated to the R\&D institute; (2) when the R\&D institute is in possession of bargaining power prior to cooperation, it shall be allocated control rights and such an allocation is effective; while when the sponsoring enterprise is in possession of bargaining power prior to cooperation (in other words, the R\&D institute is lack of funds), the sponsoring enterprise might be attempted to grab the property rights of innovation outcome (usually in an invalid way though). Therefore, the core of economic control lies in the allocation of surplus rights, which is a function of comparative marginal efficiency and bargaining power.

As in most innovation alliances, the marginal efficiency of the efforts of R\&D institutes is usually higher than that of sponsoring enterprise's investment, we 
develop, based on Aghion and Tirole's theory, the following hypothesis:

H3 In an innovation alliance, the amount of control right owned by the sponsor is negatively related to the alliance's R\&D performance.

\subsection{Control Based on Relationship Governance}

Along with the economic development, the organizing mode and final form of economic organization has been evolving continuously. Some "middle" governance mechanisms different from the former market governance and bureaucratic governance mechanisms gradually take shape, such as strategic partnership between supplier and buyer, technology franchise and alliance, etc. These middle governance mechanisms are called by some researchers as "mixed governance" (Williamson, 1991) or "networked governance" (Eccles \& Crane, 1987). Macneil (1987) found that, even with explicitly-written contract, enterprises are reluctant to use legal means to solve disputes, but to turn to norms, tradition or other code of behavior to maintain harmonious long-term relationship, out of worries that legal means are either unnecessary or costly, or might bring forth unexpected consequences. Therefore, Dwyer and Schurr (1987) proposed that in a relationship-based transaction, the foundation for future cooperation is "supported by all kinds of stated or unstated hypotheses, trust, and plans".

Relationship governance based on mutual trust of all parties involved is a form of fixed governance mechanism. In such a mechanism, a series of relational norms are adopted to define acceptable behaviors of all parties involved. Different types of relationship paradigms have been proposed by scholars. For example, Anderson and Narus (1990) proposed four relationship paradigms, namely communication, trust, dependence and cooperation. Similarly, Poppo and Zenger (2002) assumed three relationship paradigms (i.e. cooperation, dependency and objective-sharing). Aulakh, Kotabe and Sahay (1996) studied another three relationship paradigms (i.e. continuous expectation, flexibility and information communication). Among these paradigms, information sharing and continuity expectation are common paradigms, while trust and dependency can be summarized as improved relationship.

In an alliance, information sharing, namely "timely sharing of different formal or informal information among different partners in an alliance" (Anderson, Narus, 1990) plays a key part in solving disputes and improving mutual trust (Moorman et al. 1994). In addition, information sharing is beneficial to resources or capability complementarity. To technology problem in R\&D process and improve innovation performance, we develop the following hypothesis:

H4 Information sharing is beneficial to alliance performance. The degree of information sharing is positively related to $R \& D$ performance. 
"Guanxi improvement" refers to means and methods adopted by different parties in an alliance to strengthen relationship and mutual trust, such as all kinds of sports and entertainment events. Guanxi is a unique phenomenon under China's special cultural and institutional context. Good guanxi plays a key function in promoting inter-organizational cooperation. In addition, measures taken to improve mutual relationship are beneficial to information communication, which in turn improve alliance performance. Therefore, we propose the next hypothesis:

H5 Mechanisms for improving mutual relationship among R\&D alliance members are positively related to alliance performance.

Continuity expectation paradigm refers to perception of members in an alliance on the possibility of future cooperation. If all members are willing to continue the cooperation in the future, they will look for no new partners (Anderson, Weitz, 1989). In a sense, continuity expectation indicates commitment of R\&D alliance members to long-termed cooperation. Once such a commitment is built up, members would not pursue short-term interest at the cost of long-term interest. Therefore, continuity expectation is beneficial for preventing opportunistic behaviors from happening and improving $R \& D$ alliance performance. Thus,

H6 Continuity expectation is positively related to $R \& D$ alliance.

Below, we shall use data obtained from R\&D alliances in China's pharmaceutical industry to test the above hypotheses.

\section{Sample Selection and Testing Methods}

\subsection{Sample Selection and Data Sources}

The empirical work started in August, 2004. R\&D alliances in China's pharmaceutical industry were chosen as samples due to the following reasons: (1) pharmaceutical industry is a $R \& D$ intensive industry. There are many $R \& D$ alliances in the industry. (2) It takes a long time and complicated procedures for new drugs to be marketed. There are rigorous new drug classification criteria ${ }^{1}$ and strict drug approval procedures. In addition, there are sufficient literature on the innovation degree of new drugs, research circle, difficulty of drug

\footnotetext{
${ }^{1}$ Refer to http: //www.sda.gov.cn (official website of State Food and Drug Administration of China).
} 
development, and characteristics of drug development (e.g., complexity, uncertainty, change patterns, etc.) (Lerner et al., 1998).

This two-year-long study could be divided into four phases. In Phase One, with the help from the Office of Beijing Technical Market ${ }^{2}$, drug R\&D institutes or drug manufacturing enterprises in Shanghai, Chengdu, Shenyang, Guangdong, we obtained 205 R\&D cooperation contracts signed somewhere between Dec, 1999 to Dec, 2004 and fulfilled before March, 2006. By studying these contracts, we identified data of outcome control (depending on the explicitness of objective and task definition), economic control (allocation of control rights), uncertainty of technology, contract prices, etc. We also obtained other information such as sponsor enterprises' name, address, telephone number and name of persons who were in charge of the fulfillment of these contracts for the convenience of questionnaire delivery. In Phase Two, we sent a copy of questionnaire to every sponsoring enterprise in these R\&D alliances to collect data of these enterprises' process control, relationship mode choice, amount of money invested and alliance performance, etc. A total of 205 questionnaires were delivered. Due to the difficulty in obtaining these samples, we tried many means to improve the return rate of our questionnaires, such as making phone calls, writing emails, and paying visit to focus enterprises, etc. In the end, 82 valid questionnaires were returned (return rate $=40 \%$ ). In Phase Three, metric models were set up to analyze data and empirically test hypotheses. To start with, we will introduce data processing, variable selection, and measurement.

\subsection{Variable Selection and Measurement}

As above, the aims of this study are to test the effects of economic control, organizational control, and relationship governance on $R \& D$ alliance performance. Therefore, we select variables and measurement methods as follows:

\subsubsection{Dependent Variable: R\&D Alliance Performance}

AS Bates and Holton (1995) pointed out, "performance has many constructs". Therefore, the "measurement outcomes vary when different constructs are measured". Das and Teng (1996) argued that there are two factors influencing the measurement results of alliance performance. One is the degree of satisfaction of

${ }^{2}$ All technology development contracts in Beijing City are required to register in the Office of Beijing Technical Market to obtain preferential taxation policies. After signing a contract with the office promising to keep these data confidential and under the supervision of employees from the office, we obtained these contract data from the office. 
members toward alliance performance (even though alliance goals might not be completely fulfilled). The other is fulfillment of alliance goals (even though such goals might not be very satisfactory). To a large degree, things are even more complicated in a R\&D alliance. Meanwhile, considering there are great differences in goals of different $R \& D$ alliances, it is impossible to use only one indicator to measure their performance. Therefore, this paper uses the alliance members' degree of satisfaction and degree of alliance goal fulfillment to comprehensively reflect alliance performance. Testing results show that the Cronbach Alpha is 0.81 . Specific questions used in the questions are as follows:

(1) As a whole, we are very satisfied with the results of the new drug development cooperation.

(2) This cooperation has fulfilled our anticipated goals.

In our regression model, the mean of the above two items are used to measure the performance of $R \& D$ alliance.

\subsubsection{Independent Variable}

Economic control. As shown in the above literature review, economic control in a R\&D alliance is based on the incomplete contract theory. The validity of this control approach depends on allocation of control rights. Therefore, economic control is measured based on the number of control rights a sponsoring enterprise obtains. Drawing on Liu and Ma's (2004) detailed definition of control rights in China's pharmaceutical industry, we list 18 important control rights in Table 1.

Table 1 Important Control Rights in New Drug Development Alliances in China's Pharmaceutical Industry

\begin{tabular}{|c|c|}
\hline $\begin{array}{l}\text { (1) Right of clinical trials management } \\
\text { (2) Right of technology development } \\
\text { (3) Right of final product manufacturing } \\
\text { (4) Right of product marketing and sales } \\
\text { (5) Right of alliance expansion } \\
\text { (6) Right of alliance contract extension } \\
\text { (7) Right of special project termination } \\
\text { (8) Right of refranchise } \\
\text { (9) Intellectual property right }\end{array}$ & $\begin{array}{l}\text { (10) ownership right to part of intellectual property } \\
\text { rights } \\
\text { (11) Right of know-how transfer } \\
\text { (12) Ownership of core technology } \\
\text { (13) Right of delay declaration } \\
\text { (14) Right of declaration prohibition } \\
\text { (15) Right of authorship on new drug certificate } \\
\text { (16) Right of declaration of scientific research } \\
\text { progress and ownership right of the progress } \\
\text { (17) Right of participation in R\&D as sponsor } \\
\text { (18) Right of sponsor training }\end{array}$ \\
\hline
\end{tabular}

Source: Liu and Ma (2004).

Outcome control. Data of outcome control were obtained from the above technology development contracts. The degree of project contents and technology indicators description explicitness are used as two key factors of outcome control. 
Three members of this research team mark separately each of the two factors (ranging from 1 to 5). Means of these marks are calculated as final marks. Further discussion is used to solve any discrepancy exists among these marks. In the regression model, the value of outcome control is calculated by adding the points of the above two key factors.

Process control. Process control is used to measure the strength of control of sponsor exert over $R \& D$ partners in a $R \& D$ alliance. By gaining a better understanding of the research progress, managing the research progress and evaluate primary data and other means, sponsoring enterprise are able to supervise and control contract fulfillment process. This study identifies process control from four aspects (as shown below) and obtains data by sending questionnaires to sponsoring enterprises. The Cronbach's Alpha of the questionnaire is 0.76 .

Items in the questionnaires are:

(1) When fulfilling a contract, we always use meeting, telephone and emails to communicate with one another.

(2) When fulfilling a contract, we conduct formal check on research progress on both regular and irregular basis.

(3) When fulfilling a contract, we often send people to our R\&D partner to supervise research progress.

(4) When fulfilling a contract, we lay great emphasis on the checking of the experiment documents and primary data of research program.

In the regression mode, the value for process control is the mean of the above four items.

Relationship deepening. As $R \& D$ alliance is cooperation between two independent organizations. Enhancement of mutual relationship will affect positively trust and confidence in one another, which in turns helps improve alliance performance. There are two items concerning relationship deepening (as shown below). The Cronbach's Alpha of these two items is 0.59 .

Concrete items concerning relationship deepening in the questionnaires are:

(1) We believe it is very important to build up good relationship and friendship with our partners when fulfilling a contract.

(2) We often carry out all kinds of activities to build up good friendship with our partners when fulfilling a contract, such as going out to eat together or participate in other entertainment activities.

The means of the above two items are used to measure the variable of relationship deepening in regression model.

Information sharing. One of the striking characteristics of R\&D alliance is information asymmetry. It increases greatly alliance management cost and 
performance. We use two items to measure information sharing (Cronbach's Alpha $=0.77)$.

Specifically, items measuring information sharing are:

(1) When fulfilling a contract, we are unwilling to provide additional information to our researcher partners other than what is required by the contract.

(2) When fulfilling a contract, our R\&D partner is unwilling to provide additional information to us other than what is required by the contract.

As above, the means (reversed) of the two items are used in the regression model.

Continuity expectation. Continuity expectation affects alliance members' input into an alliance, including both material and intellectual investment. Taken together, continuity expectation helps avoid alliance members' opportunistic behaviors, reduce supervision cost and improve alliance performance. In our questionnaire, three items are used to measure continuity expectation (Cronbach's Alpha $=0.67$ ).

The three items are, respectively:

(1) When fulfilling a contract, we will make promises to our partners to conduct our responsibility and try utmost to keep these promises.

(2) When fulfilling a contract, there is high degree of uncertainty existing in our cooperation with $R \& D$ institutes.

(3) When fulfilling a contract, we are not sure how long will these cooperation relationships last.

Adjusted means of the above three items are used to measure the variable of continuity expectation in our regression model.

\subsection{Control Variables}

Technology uncertainty. The uncertainty in technology development is an important reason inducing opportunistic behaviors in R\&D alliances. Generally speaking, the uncertainty of new drug development has something to do with the innovation difficulty and the specific development stage of a new drug when a $R \& D$ contract is signed. As a rule, the more difficult the innovation, the higher the innovation uncertainty; and the earlier the development stage, the higher the innovation uncertainty. Since May 1994, drug classification, appraisal and administration have been following the Approval Procedure of New Pharmaceuticals issued by the State Food and Drug Administration of China in May, 1994. The procedure defined new drug as "those manufactured in China, or manufactured abroad but has been changed in one way or another since importation are regarded as new drugs." In addition, the administration classified drug in China into five types in accordance with traditional medicine and 
chemical medicine. Among the five types, Type One refers to those drugs new to the market both at home and abroad. This type of drug has the highest degree of complexity and innovation and requires highest amount of reach and development. Type Five has the lowest degree of complexity and innovation. According to the degree of innovation difficulty and technology complexity, we mark the above five types of medicine, from Type Five to Type One, as 5, 4, 3, 2,1, respectively. Drawing on Lerner and Merges' (1998) study, we divide development of a new drug into four phases, namely, discovery, chemical composition and screening, pre-clinical development, clinical study, appraisal, and marketing phase (marked as 4,3,2 and 1 respectively). The earlier a phase is along the drug development line, the more difficult and complex the innovation will be.

In our model, the value for technology uncertainty ranges from 1 to 5 .

Size of sponsoring enterprise. The sales revenues of a sponsoring enterprise in the year prior to the establishment of R\&D alliance is used as an indicator of a sponsoring enterprise's size. Specifically, a sponsoring enterprise with an annual sales revenue smaller than 50 million yuan is regarded as a small enterprise (coded as 1), between 50 million yuan and 100 million yuan is medium-sized enterprise (coded as 2), above 100 million yuan is big sized enterprise (coded as 3).

Technology price. Technology price is categorized as follows: technology traded at a price lower than 0.5 million yuan is coded as 1 ; between 0.5 million yuan and 2 million yuan is coded as 2 ; above 2 million yuan is coded as 3 .

Pre-alliance relationship closeness. Lui and Ngo (2004), when studying the relationship between non-shareholding alliance trust and contract protection, argued that pre-alliance relationship is one of the determinants of alliance performance. Based on this argument, we divide the degree of relationship closeness of alliance members before alliance formation as 1,2 and 3, among which 1 denotes the least close pre-alliance relationship, and 3 denotes the closest pre-alliance relationship.

\subsection{Correlation Analysis}

Descriptive statistics and correlation coefficients are in Table 2.

Table 2 Descriptive Statistics and Correlation Coefficients of All Variables

\begin{tabular}{llrlrrrrrrrrr}
\hline & Variables & Mean & S.D. & 1 & 2 & 3 & 4 & 5 & 6 & 7 & 8 & 9 \\
\hline 1 & Economic control & 4.80 & 2.35 & 1.00 & & & & & & & & \\
2 & Outcome control & 5.91 & 1.88 & $0.33^{* *}$ & 1.00 & & & & & & \\
3 & Process control & 3.82 & 0.69 & -0.10 & -0.08 & 1.00 & & & & & \\
4 & Relationship & 2.99 & 0.83 & -0.08 & -0.11 & -0.05 & 1.00 & & & & \\
& deepening & & & & & & & & & & & \\
\hline
\end{tabular}




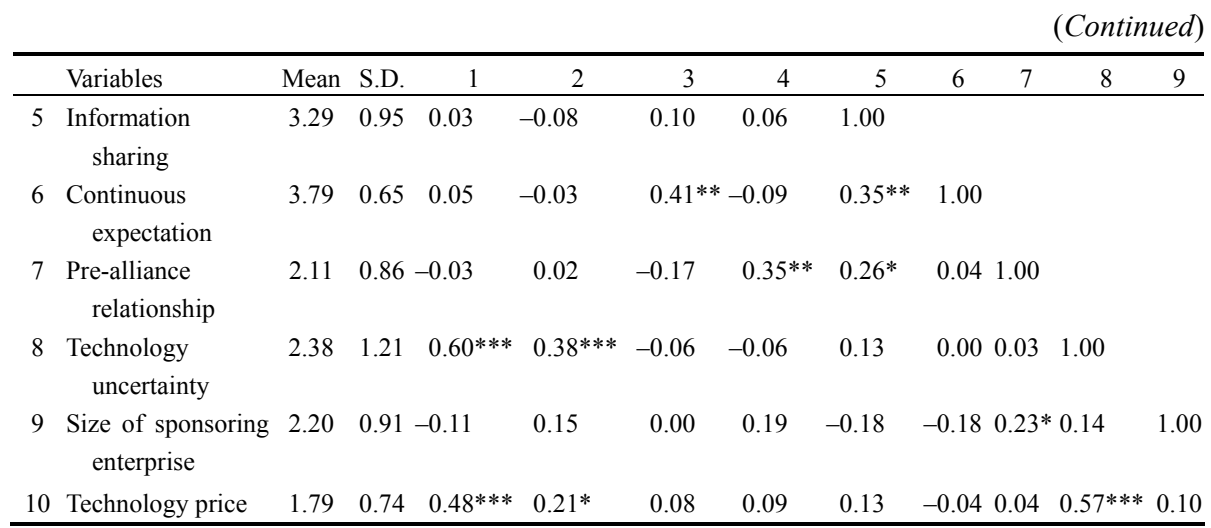

Note: $* * *$ indicates significant at 0.001 level, $* *$ indicates significant at 0.01 level, * indicates significant at 0.05 level.

Although correlation relationship does not necessarily mean causality, Table 2 does reveal a lot of important information. First, economic control is significantly and positively related to technology uncertainty, technology price, and outcome control, which indicates that the higher the degree of innovation, the earlier the development stage when alliance agreement is assigned, the more control right the sponsor obtain; in addition, the more sponsor enterprises invest, the more control rights they obtain when possessing apparent bargaining power, sponsoring enterprises can grasp as much controlling rights as possible. Second, outcome control has been found significantly and positively related to economical control, showing that the more sponsors eager to grasp more control rights, the more they are likely to define explicitly technology indexes and R\&D objectives in contracts. Third, continuity expectation is positively and significantly related to process control and information sharing, indicating that the more sponsoring enterprises wish to maintain a sustainable relationship with their R\&D partner, the more they are likely to pay attention to the contract execution process to enhance the understanding of their R\&D partner and share information with one another. In addition, there is a positive and significant relationship between amount of money invested in a project and technology uncertainty. In other words, the higher the degree of technology uncertainty (e.g., the higher the degree of drug innovation) in a project, the greater the amount of money invested in the project.

\section{Regression Analysis}

The linear regression results using alliance performance as a dependent variable is presented in Table 3. The variance inflation factor of all variables are within 2, except 
technology complexity (2.2), showing that there is no multicollinearity problem.

As shown in Table 3, there is no significant relationship between outcome control, process control and alliance performance. Thus $\mathrm{H} 1$ and $\mathrm{H} 2$ are not supported. This results show that process and outcome control are not good ways of improving alliance performance (though they might also not reduce alliance performance as well).

Economic control is significantly and negatively related to alliance performance. In other words, the more control rights possessed by sponsoring enterprise, the lower the alliance performance. H3 is supported. This result is consistent with Aghion and Tirole's hypothesis: when the marginal efficiency of R\&D partner is higher than that of marginal efficiency of sponsoring enterprise, the control rights should be allocated to the R\&D partner; however, when R\&D institutes lack of funds and sponsoring enterprise thus have bargaining power prior to alliance formation, sponsoring enterprise might be attempted to possess property rights in vain.

There is a positive and significant relationship between relationship deepening and continuity expectation. This result supports H5 and H6. In other words, in R\&D alliance characterized by higher degree of uncertainty, wishes to further deepen relationship and cooperate for a longer time play a vital role in enhancing alliance performance. Such a finding supports Macneil (1978) and Levin's (2003) viewpoint: technology contract is based on good relationship, which means its execution is dependent on all parties' effort and wish of maintaining long-term relationship. Information sharing does not have any significant relationship with alliance performance. Thus, $\mathrm{H} 4$ is not supported.

Table 3 Relationship among Control Strategy, Relationship Mode and Alliance Performance

\begin{tabular}{|c|c|c|}
\hline & Coefficient & ( $T$ Value) \\
\hline Intercept & 1.2340 & 1.37 \\
\hline \multicolumn{3}{|l|}{ Independent Variables } \\
\hline Economic control & -0.13345 & $-2.42 * *$ \\
\hline Outcome control & 0.04608 & 0.81 \\
\hline Process control & -0.11677 & -0.73 \\
\hline Relationship deepening & 0.33218 & $2.63 * *$ \\
\hline Information sharing & 0.09185 & 0.78 \\
\hline Continuous expectation & 0.60410 & $3.45 * * *$ \\
\hline \multicolumn{3}{|l|}{ Control variables } \\
\hline Pre-alliance relationship & -0.23888 & $-1.84^{*}$ \\
\hline Technology compexity & 0.11087 & $0.96 * *$ \\
\hline Size of the sponsoring enterprise & 0.0633 & 0.52 \\
\hline Amount of money invested & -0.12632 & -0.76 \\
\hline \multicolumn{3}{|l|}{ Total significance } \\
\hline$F$ Value & & \\
\hline$R^{2}$ & & \\
\hline Adjusted $R^{2}$ & & \\
\hline
\end{tabular}

Note: $* * *$ indicates significant at 0.001 level, $* *$ indicates significant at 0.01 level, * indicates significant at 0.05 level. 
Among the control variables, pre-alliance relationship has been found negatively connected with alliance performance. In other words, close pre-alliance relationship is bad for alliance performance improvement. We will discuss this counter-intuitive finding in another article named "Initial Trust and Control Strategy of R\&D Alliance".

\section{Conclusion and Discussion}

This study uses data of R\&D alliance in China's pharmaceutical industry to examine whether control-based or relationship-based approaches could improve alliance performance. Main conclusions are listed as follows:

First, unreasonable economic control is harmful to alliance performance. In other words, the more control rights held by the sponsoring enterprises, the more likely that the R\&D parties' research enthusiasm might be hurt, which in turn weakens the final $R \& D$ alliance performance.

Second, there is no proof showing that organizational control means, including process control and outcome control, are negatively related to alliance performance in alliances characterized by high degree of technology uncertainty.

Third, activities aiming at deepening relationship and enhancing friendship among alliance members are beneficial to the improvement of alliance performance.

Fourth, continuity expectation is useful in reducing alliance members' opportunistic behaviors and ethic risks and in improving alliance performance. Therefore, to build a long-term relationship needs to pay attention to both short-term interest and long-term cooperation, which is of great significance to the establishment and maintenance of a sustainable alliance relationship.

This paper does not find evidence showing that process and outcome control hurt alliance performance, nor do them help improve alliance performance. These results show that we still need to further explore these control approaches.

When sponsoring enterprises are in possession of bargaining power in negotiation, they shall take care not to abuse their power. In other words, sponsoring enterprises shall pay attention to both their own interest and their R\&D partners'. Otherwise, R\&D institutes in the alliance will be demotivated to fulfill their contracts. Therefore, sponsoring enterprises shall be more careful in designing and allocating control rights in a $\mathrm{R} \& \mathrm{D}$ alliance, as control rights play a vital part in motivating all alliance members.

Motivation-based control approaches, including allocating control rights properly, increasingly enhancing continuity expectation, and constantly improving mutual friendship, are better ways to meliorate alliance performance than organizational control. 
Acknowledgements This work is part of a research program supported by the Beijing Municipal Science \& Technology Commission.

\section{References}

Aghion P, Tirole J (1994). On the management of innovation. Quarterly Journal of Economics, 109: $1185-1209$

Anderson J C, Narus J A (1990). A model of distributor firm and manufacturing firm working partnerships. Journal of Marketing, 54: 42-58

Andrew C I, Currall S C (2004). The coevolution of trust, control, and learning in joint ventures. Organization Science, 15(5): 586-599

Aulakh P, Kotabe M, Sahay A (1996). Trust and performance in cross-border marketing partnerships: A behavioral approach. Journal of International Business Studies, 27(5): $1005-1032$

Das T K, Teng B S (2001). Trust, control, and risk in strategic alliances: An integrated framework. Organization Studies, 22(2): 251-283

Dwyer F, Schurr R, Paul H, Oh S (1987). Developing buyer-seller relationships. Journal of Marketing, 51(April): 11-28

Eccles R G, Crane D B (1987). Managing through networks in investment banking. California Management Review, 30(1): 176-195

Eisenhardt K M (1985). Control: Organizational and economic approaches. Management Science, 31(2): 134-149

Grossman S, Hart O (1986). The costs and benefits of ownership: A theory of vertical and lateral integration. Journal of Political Economy, 94(4): 691-719

Gulati R (1995). Does familiarity breed trust? The implications of repeated ties for contractual choice in alliances. Academy of Management Journal, 38: 85-112

International Institute for Management Development (IMD) (2003). World Competitiveness Yearbook

International Institute for Management Development (IMD) (2005). World Competitiveness Yearbook

Jonathan L (2003). Relational incentive contracts. The American Economic Review, 93(3): $835-857$

Lerner J, Merges R P (1998). The control of technology alliances: An empirical analysis of the biotechnology industry. The Journal of Industrial Economics, 46(2): 125-156

Lui S, Ngo H (2004). The role of trust and contractual safeguards on cooperation in non-equity alliance. Journal of Management, 30(4): 471-485

Macneil I R (1978). Contracts: Adjustment of long-term economic relations under classical and relational contract law. Northwestern University Law Review, 72(6): 854-905

Moorman C, Deshpandé R, Zaltman G (1993). Factors affecting trust in market research relationships. Journal of Marketing, 57(1): 81-101

Morgan R M, Hunt S D (1994). The commitment-trust theory of relationship marketing. Journal of Marketing, 58(3): 20-38

OECD (1991). The nature of innovation and the evolution of the productive system. technology and productivity - The challenge for economic policy. Paris: OECD, 14-303

Ouchi W (1979). A conceptual framework for the design of organizational control mechanisms. Manage Science, 25: 833-848 
Poppo L, Zenger T (2002). Do formal contracts and relational governance function as a substitutes or complements? Strategic Management Journal, 23: 707-725

Lui S S, Ngo H Y (2004). The role of trust and contractual safeguards on cooperation in non-equity alliances. Journal of Management, 30(4): 471-485

Williamson O E (1991). Transaction cost economics and organization theory. Industrial and Corporate Change, (2): 107-156

刘学 (Liu Xue) (2001). 企业技术的获得: 内部化与市场的优劣势比较 (Getting technologies: A comparison between advantages and disadvantages of internalization and market). 科技导报, (8): $38-41$

刘学, 马宏建 (Liu Xue, Ma Hongjian) (2004). 研究开发联盟中的控制权配置: 中国制药产业的 研究 (Control rights allocation in R\&D alliance: Research of China's pharmaceutical industry). 数量经济技术经济研究, (6): 28-38 